\title{
Identifying and ranking the risks of implementing Computerized Maintenance Management System by AHP method with Fuzzy Approach (Case Study: Amirkabir Petrochemical Company- Mahshahr)
}

\author{
Mohammad Javad Khodadadi \\ Department of Industrial engineering, Mahshahr Branch, \\ Islamic Azad University, Mahshahr, Iran \\ mohammad.j.khodadadi@gmail.com \\ Dr. Mahmood As'ad Samani \\ Central Insurance of Islamic Republic of Iran \\ samani002@gmail.com \\ Dr. Seyed Mojtaba Zabihinpour jahromi \\ Andisheh Institute of highes education, Jahrom \\ mojtaba.zabihi@gmail.com
}

\begin{abstract}
The current study identifies and ranks the risks of implementing a Computerized Maintenance Management System (CMMS) using AHP method with fuzzy approach. In organizations, uncertainty and fundamental challenges such as the lack of information and sufficient knowledge about computerized maintenance management system create some factors in the organization that affect directly the implementation of system. These factors are known as CMMS implementation risks. In order to identify these factors, library studies and interview with experts and specialists were used and for weighingand ranking the factors, fuzzy AHP methods were used (Buckley and Chang). The results show that Chang's fuzzy Algorithm is not proper for this study due to the existence of zero weights in the final results, and in this algorithm, risks and factors "determining the goals of organization", "determining needs and creating proper background", "culturalization and comprehensive education for users" and "compilation and implementation of comprehensive guidelines" are very important, and the factors of "creating a strong database" and "having specializedhuman resources" are less important. Finally, the rate of applying the identified and ranked factors in the research for the CMMS implemented in Amir Kabir Petrochemical Company was investigated and specifiedthat the identification and and prioritization of the factors have not been done properly, and the fundamental and high-priority factors were conducted poorly and as a result, this led to the dissatisfaction and failure of the project of Computerized Maintenance Management System.
\end{abstract}

Keywords: Computerized Maintenance Management System, risk, maintenance

\section{Introduction}

The existence of the various and complex manufacturingtechnologies in organizations causes various demands from individuals in organizations that should be met through a proper structure. The demand from Maintenance Management in organizations includes the activities ensuring the process of production and services. In fact, Maintenance Management is planning and implementing the activities related to maintenance of means and equipment effectively that requires creating the Computerized Maintenance Management System By which the technical and economic information of the activities of Maintenance Management are stored and analyzed (Lopez et al, 2017). In recent decades, implementing the Computerized Maintenance Management System (CMMS) that is "using computer technology for accurately and effectively managing the physical assets in the framework of planning informational, administrative and executive affairs of Maintenance Management, and buying and controlling the inventories, spare parts and consumable equipment of it" has been considered widely, so that most of the petroleum companies prioritize implementing this system than other plans. The goal of establishing Maintenance Management unit is to minimize human resources costs, materials and reduce producing pauses in organization. Maintenance Management is a complex and multi-aspects task implemented 
parallel to producing operations. Computerized Maintenance Management System is usually used to supervise and control these tasks (Herbaty, 1990).

There are various software for asset management and maintenance, and reviewing research and experiments show that most of the designed software has high capability, but the main factor of failure of CMMS software is related to the manner of its designing and implementing (Zare et al, 2018). Hence designing and implementing the Computerized Maintenance Management System is a new project and work, and beginning any new movement and work is not possible simply and encounters challenges and barriers naturally (Karimi and Kolahiranji, 2015). Regardless of type and size, organizations encounter internal and external influential factors which make their achieving at goals and the time of it uncertain. The effect of this uncertainty on the organization's goals is called "risk" (ISO 31000, 2009). The importance of the need to examine the available challenges of CMMS is related to the fact that the implementation of these systems is an investment to improve the organization's asset and maintenance management system. If it is not managed and guided correctly, it can sometimes be not only non-beneficial to the organization, but also be dangerous for it (Soodani and Rezaei, 2018). Identifying risks and factors affecting the implementation of Computerized Maintenance Management System in large petrochemical companies is imperative and the lack of determination and setting proper policies for the organization's implementing CMMS, the required methods and strategies and priorities correctly are the most important reasons for implementing Computerized Maintenance Management Systems (Maktoobian, 2015). Risk identification and ranking help to make correct decision for choosing security solutions and orientate correctly in choosing solutions (that is removing the main threats) (Farahani and Gonei, 2010).

MalekiNejad and Hamta (2017) concluded from their research that many factors affect the Computerized Maintenance Management System including: lack of equipment control, lack of proper maintenance information, lack of organizational managers' support, lack of labor efficiency, lack of education and making the CMMS system understood by members of organization. Then using the fuzzy AHP algorithm, they prioritize the factors and the results show that the criterion of lack of specialized and trained human resource for guiding and implementing CMMS programs has the greatest effect on inefficiency of the system MalekiNejad and Hamta (2017). Fortin (2018) considers education as the most important step of success and shows the way of the correct and optimal use of CMMS for management and staff of airport to achieve at goals and success in implementing (Fortin et al, 2018). Wisniewski and Blaszczyk (2018) state that informational technology system is the most important tool for implementing the CMMS system. Wienker et al. (2016) show that the successful implementation of CMMS system entails a previously managed program (Wienker et al, 2016).

According to some dissatisfaction with the Computerized Maintenance Management System implemented in Amir Kabir Petrochemical Company and that the risks of implementation of CMMS software in petrochemical industries, specially Amirkabir petrochemical industry in Mahshahr, have not been investigated in any study so far, so the purpose of this paper is identifying the factors affecting the success and failure of the implementation of the CMMS system and also ranking and prioritizing the factors by applying the hierarchical analysis process (AHP7) method and a fuzzy approach.

\section{Research methodology}

The present study identifies and ranks the risks of implementing Computerized Maintenance Management System by AHP fuzzy method and an approach using Buckley and Chang algorithms and then compares the results and introduces the effective factors for better managing and controlling. In this research, in order to gather information and data in organization, we used a combination of library and field studies including interviews and questionnaires.

The statistical population consists of all senior members of the maintenance management unit with an organizational rank of 16 or above, and sampling was based on formula 1 (Cochran method with a specific population size) and the sample size includes 14 prominent officials and experts of Amir Kabir petrochemical company.

$$
\mathrm{n}=\left(\mathrm{Nz}^{2} \mathrm{~s}^{2}\right) /\left(\mathrm{Nd}^{2}+\mathrm{Z}^{2} \mathrm{~s}^{2}\right)
$$

Where $\mathrm{n}$ is the sample size, $\mathrm{N}$ is the population size including 14 people, $\mathrm{z}$ is the confidence level considered as $95 \%$, $\mathrm{d}$ is error margin (Tolerance) with value of $0 / 05$ and $\mathrm{s}$ is the standard deviation considered as 0/5 (Habibi, 2012).

In this research, a variety of tools have been used to gather information, the most important of which is presenting questionnaire to prominent experts and managers of Amir Kabir petrochemical company formed as following:

Questionnaire 1: This questionnaire has been compiled to determine the risks and factors that are effective to evaluate Computerized Maintenance Management System.

Questionnaire 2: This questionnaire has been designed to weigh the risks and the effective factors determined in the previous step and then enter the high-scored factors into the research. 
Questionnaire 3: This questionnaire has been compiled to specify the importance of factors relative to each other (paired comparisons).

Questionnaire 4: This questionnaire has been designed to specify the rate of factors affecting the implementation of the CMMS system applied in Amir Kabir Petrochemical Company.

This research was conducted according to the steps of Chart 1 :

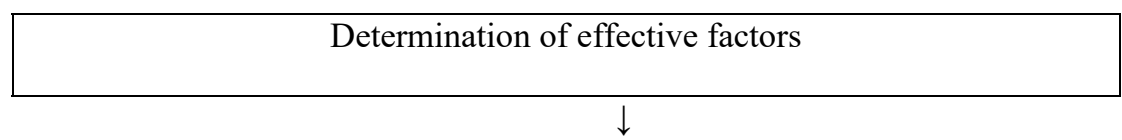

Selection of factors proportionate with Amir Kabir Petrochemical Company

$\downarrow$

\begin{tabular}{|c|}
\hline Completion of the matrix of factors paired comparisons \\
\hline
\end{tabular}

Calculation of the inconsistency rate

$\begin{gathered}\text { Computation by Fuzzy AHP Method (Famous Fuzzy Methods of } \\ \text { (Chang) and (Buckley)) }\end{gathered}$
$\downarrow$

\begin{tabular}{|c|}
\hline Comparison between Chang and Buckley Fuzzy Methods \\
$\downarrow$
\end{tabular}

Investigating the rate of observance of factors effective on CMMS implementation in Amir Kabir Petrochemical Co.

Chart 1- the steps of research

\section{Calculation of the inconsistency rate for fuzzy numbers}

Two researchers named Gogus and Boucher (1998) have provided a method for calculating the rate of consistency of the matrices of fuzzy paired comparisons. In this method, in order to examine the consistency, it is required to divide every paired comparison matrix into two distinct matrices. Since these matrices include numerical data (non-fuzzy), the method of Thomas L. Saaty can be used to calculate the weight vector. So firstly, the matrix of fuzzy paired comparison is divided into two definite matrices, and then by the method of Saaty, the inconsistency rate of each definite matrix will be calculated based on the random index of Table 1 (Gogus and Boucher, 1998).

Table 1- random index of Gogus and Boucher

\begin{tabular}{|c|c|c|c|c|c|c|c|c|c|c|c|c|c|c|c|}
\hline $\mathbf{n}$ & $\mathbf{1}$ & $\mathbf{2}$ & $\mathbf{3}$ & 4 & 5 & 6 & 7 & 8 & 9 & 10 & 11 & 12 & 13 & 14 & 15 \\
\hline $\boldsymbol{R} \boldsymbol{I}_{\boldsymbol{m}}$ & $\mathbf{0}$ & $\mathbf{0}$ & $\mathbf{0 . 4 8 9}$ & $\mathbf{0 . 7 9 3 7}$ & $\mathbf{1 . 0 7 2}$ & $\mathbf{1 . 1 9 9 6}$ & $\mathbf{1 . 2 8 7 4}$ & $\mathbf{1 . 3 4 1}$ & $\mathbf{1 . 3 7 9 3}$ & $\mathbf{1 . 4 0 9 5}$ & $\mathbf{1 . 4 1 8 1}$ & $\mathbf{1 . 4 4 6 2}$ & 1.4555 & $\mathbf{1 . 4 9 1 3}$ & 1.4986 \\
\hline $\boldsymbol{R} \boldsymbol{I}_{\boldsymbol{g}}$ & $\mathbf{0}$ & $\mathbf{0}$ & $\mathbf{0 . 1 7 9 6}$ & $\mathbf{0 . 2 6 2 7}$ & $\mathbf{0 . 3 5 9 7}$ & $\mathbf{0 . 3 8 1 8}$ & $\mathbf{0 . 4 0 9}$ & $\mathbf{0 . 4 1 6 4}$ & $\mathbf{0 . 4 3 4 8}$ & $\mathbf{0 . 4 4 5 5}$ & $\mathbf{0 . 4 5 3 6}$ & $\mathbf{0 . 4 7 7 6}$ & $\mathbf{0 . 4 6 9 1}$ & $\mathbf{0 . 4 8 0 4}$ & $\mathbf{0 . 4 8 8}$ \\
\hline
\end{tabular}

Buckley Fuzzy Algorithm

According to the initial failures of the fuzzy AHP method, Buckley developed a new method to fuzzy the AHP technique in 1985. This method is called Buckley geometric mean method (Buckley, 1985).

The steps of Buckley geometric mean method, known as the improved method, are: Step 1: First, by choosing the intended fuzzy spectrum according to table 2, the collected data enters the paired comparison matrix (Aczel and Saaty, 1983). 
Table 2- fuzzy spectrum equivalent to nine degrees scale of Saaty

\begin{tabular}{|lcc|}
\hline Comparing I with j state & fuzzy equivalent & reversed fuzzy equivalent \\
\hline The same importance & $(1,1,1)$ & $(1,1,1)$ \\
\hline Intermediate & $(1,2,1)$ & $(0.333,0.5,1)$ \\
\hline Relatively preferred & $(2,3,4)$ & $(0.25,0333,0.5)$ \\
\hline Intermediate & $(3,4,5)$ & $(0.2,0.25,0.333)$ \\
\hline much preference & $(4,5,6)$ & $(0.166,0.2,0.25)$ \\
\hline Intermediate & $(5,6,7)$ & $(0.142,0.16,0.2)$ \\
\hline Very much preference & $(6,7,8)$ & $(0.125,0.142,0.166)$ \\
\hline Intermediate & $(7,8,9)$ & $(0.111,0.125,0.142)$ \\
\hline Absolute importance & $(9,9,9)$ & $(0.111,0.111,0.111)$ \\
\hline
\end{tabular}

Step 2: If there are more than one expert, the geometric mean in accordance with Formula 2 is used to combine the experts' views.

$$
\left(\Pi_{\mathrm{i}=1}^{\mathrm{n}} \mathrm{a}_{\mathrm{i}}\right)^{1 / n}=\sqrt{ } a 1 a 2 a 3 \ldots \text { an }
$$

Where $\mathrm{n}$ is the number of comments and $a i$ is the values related to the comment of ith experts.

Step 3: In the paired comparison matrix resulted from the aggregation of the experts' views, the geometric mean of elements of each raw are calculated according to formula 2 and the fuzzy sum of total preference of the elements is obtained.

Step 4: Since the values are fuzzy, formula 3 is used to calculate the weight of each element: (Geometric mean of each row divided by total geometric mean).

$$
S_{\mathrm{i}}=\frac{\left[\prod_{j=1}^{n} a_{i j}\right]}{\left[\sum_{i=1}^{n} \prod_{j=1}^{n} a_{i j}\right]}
$$

whereaij is the geometric mean of the components at $\mathrm{i}$-th row and $\mathrm{j}$-th column.

Note: The divide base in the triangular fuzzy method $(1, \mathrm{~m}, \mathrm{u})$ for the inverse matrix and normalized matrix is as $\mathrm{u} / \Sigma \mathrm{l}, \mathrm{m} / \Sigma m, \mathrm{l} / \Sigma \mathrm{u}$.

Step 5: The calculated weight is the final weight of the studied element. These weights are fuzzy and to calculate the definite weight, the fuzzy method of Zadii and formula 4 are used:

$$
\mathrm{W}_{\mathrm{i}}=l+2 m+u / 4 \quad i=1,2, \ldots, m
$$

Where $\left(\mathrm{l}_{\mathrm{i}}, \mathrm{m}_{\mathrm{i}}, \mathrm{u}_{\mathrm{i}}\right)$ are the triangular fuzzy numbers related to the $\mathrm{i}$-th criterion.

Step 6: The linear normalization of the obtained definite weights is calculated according to formula 5: (dividing each weight by the total weight)

$$
n_{i}=\frac{W_{i}}{\sum_{i=1}^{m} W_{i}}
$$

Where $w i$ is the final weight of the $\mathrm{i}$-th component.

\section{Chang fuzzy Algorithm}

This method is known as the developed method of Chang in which, similar to Buckley fuzzy method, the used fuzzy numbers are extracted from the fuzzy spectrum of table 3. One of the key elements in FAHP technique by the extended method of Chang is calculation of feasibility degree (Chang, 1996).

In addition to its complexity and long calculations, Chang's method has many drawbacks. It seems that this method gives correct results only in some certain circumstances. There are some basic drawbacks involved in these calculations:

The weights of some criteria may be negative; in many cases, the weights of some criteria become zero; in some cases, non- real weights are obtained too.

The steps of Chang fuzzy method are:

According to diagram 2, consider two triangular fuzzy numbers of $\mathrm{F} 1=(11, \mathrm{~m} 1, \mathrm{u} 1)$ and $\mathrm{F} 2=(12, \mathrm{~m} 2, \mathrm{u} 2)$ : 


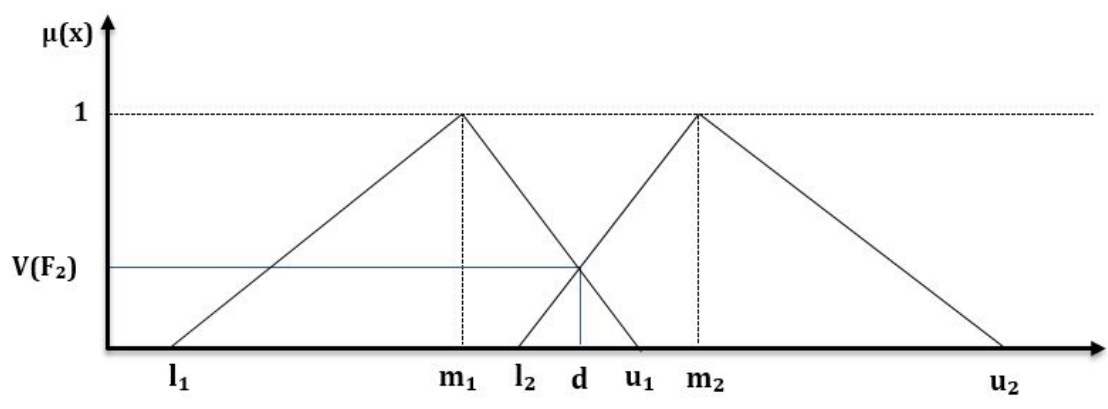

Chart 2- The probability value of greatness of two fuzzy numbers than each other.

If $m_{1} \geq m_{2}$, this probability that $F 1$ is greater than $F 2$ is 1 and the probability that $F 2$ is greater than $F 1$ equals the height of the common area of F1 and F2.

Step 1: Calculating the inverse matrix: sum of comments multiply by the inverse of the sum of comments.

Step 2: Calculating the probability of greatness of two fuzzy numbers than each other.

The probability value of greatness of F1 than F2 is calculated based on Formula 6:

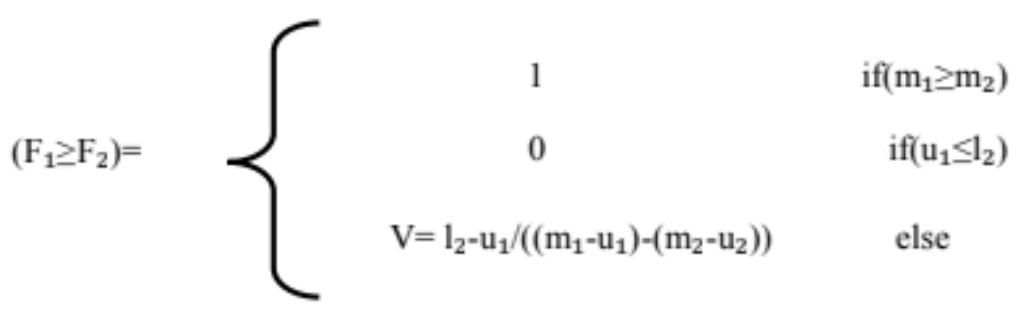

Similarly, the probability value of greatness of F2 than F1 is calculated based on Formula 7:

$$
\left(F_{2} \geq F_{1}\right)=\left\{\begin{array}{cr}
1 & \text { if }\left(m_{1} \geq m_{2}\right) \\
0 & \text { if }\left(u_{1} \leq l_{2}\right) \\
V=l_{1}-u_{2} /\left(\left(m_{2}-u_{2}\right)-\left(m_{1}-u_{1}\right)\right) & \text { else }
\end{array}\right.
$$

Note: The min value of any paired comparison (based on formulas 6 and 7) is considered the weight of each factor.

Step 3: For ranking, final weight of factors (The weight of each factor divided by the total weight) is obtained based on formula 8 :

$$
W_{i}=\frac{\min _{i}}{\sum_{i=1}^{12} \min _{i}}
$$

\section{Findings}

At this phase, after library studies and based on Questionnaire 1, 22 effective factors have been identified according to Table 3, and then based on questionnaire 2, 12 factors having the score and importance above 3 based on table 4, selected to enter to the research and in the calculations phases, shown by components E1 to E12 for simplicity: 
Table 3- the list of the effective agents and their scores

\begin{tabular}{|c|c|c|}
\hline Row & effective agents & score \\
\hline 1 & determining goals according to organization's strategies & 5 \\
\hline 2 & attention and commitment of the senior management of organization & 4 \\
\hline 3 & establishment a management committee & 5 \\
\hline 4 & establishing a consistent and expert working group & 3 \\
\hline 5 & assessing needs and creating a proper background & 5 \\
\hline 6 & planning and preparing a checklist for selecting appropriate software & 1 \\
\hline 7 & choosing the correct software & 5 \\
\hline 8 & strong programming for gradually implementing the software & 4 \\
\hline 9 & creating a strong database & 3 \\
\hline $\begin{array}{l}10 \\
\text { affairs }\end{array}$ & $\begin{array}{l}\text { compiling comprehensive guidelines for Implementing and controlling the mainten } \\
5\end{array}$ & ance management \\
\hline 11 & having expert human resources & 4 \\
\hline 12 & proper organizational structure & 1 \\
\hline 13 & personnel cooperation to launch the system & 2 \\
\hline 14 & culturalizationand comprehensive education for users & 5 \\
\hline 15 The & informational structure required for documenting the results of maintenance activities & 4 \\
\hline 16 dete & rmining the duties and powers of all users & 2 \\
\hline 17 & Flexibility and readiness for changing & 2 \\
\hline 18 & method of reporting and analyzing & 1 \\
\hline 19 & performing compliance instructions in standard direction & 2 \\
\hline \multicolumn{2}{|r|}{ 20establishing an encouragement and punishment system for all users } & 1 \\
\hline $\begin{array}{l}21 \\
2 \\
\end{array}$ & \multicolumn{2}{|c|}{ participating of all users in the direction of dynamic and continuous improvement of software } \\
\hline $\begin{array}{l}22 \text { deter } \\
\text { system }\end{array}$ & $\begin{array}{c}\text { mining the performance key indices to measure and improve effectiveness of mainten } \\
3\end{array}$ & nce management \\
\hline
\end{tabular}

Table 4- the list of selected agents for researching

\begin{tabular}{|llc|}
\hline Row & \multicolumn{1}{c|}{ agents } & equivalent component \\
\hline 1 & determining goals of organization & E1 \\
\hline 2 & management commitment & E2 \\
\hline 3 & forming management committee and expert working group & E3 \\
\hline 4 & assessing needs and creating a proper background & E5 \\
\hline 5 & choosing the correct software & E6 \\
\hline 6 & programming for gradually implementing the software & E7 \\
\hline 7 & creating a strong database & E8 \\
\hline 8 & compiling and performing comprehensive guidelines & E10 \\
\hline 9 & having expert human resources & E11 \\
\hline 10 & culturalizationand comprehensive education for users & E12 \\
\hline 11 & informational structure required for documenting the results & \\
\hline 12 & determining the performance key indices & \\
\hline
\end{tabular}

Then the paired comparison matrix was completed as fuzzy numbers according to questionnaire 3 and after various studying and interviews, and based on Tables 5 and 6 , the inconsistency rate for the middle, the upper and the lower matrices were calculated and the values of 0.069 and 0.0998 were obtained respectively, that were less than 0.1 and approved. 
Table 5- Calculating the inconsistency rate of the middle matrix of fuzzy numbers

\begin{tabular}{|l|l|}
\hline$\lambda 1$ & 13.12 \\
\hline$\lambda 2$ & 13.21 \\
\hline$\lambda 3$ & 13.10 \\
\hline$\lambda 4$ & 13.75 \\
\hline$\lambda 5$ & 12.80 \\
\hline$\lambda 6$ & 12.91 \\
\hline$\lambda 7$ & 13.01 \\
\hline$\lambda 8$ & 12.62 \\
\hline$\lambda 9$ & 12.81 \\
\hline$\lambda 10$ & 12.81 \\
\hline$\lambda 11$ & 13.06 \\
\hline$\lambda 12$ & 13.95 \\
\hline$\lambda$ max & 13.10 \\
\hline Inconsistency index & 0.100 \\
\hline Random Inconsistency index (from table 1) & 1.446 \\
\hline Inconsistency rate & 0.069 \\
\hline
\end{tabular}

Table 6- Calculating the inconsistency rate of the upper and lower matrices of fuzzy numbers

\begin{tabular}{|l|l|}
\hline$\lambda 1$ & 12.63 \\
\hline$\lambda 2$ & 12.63 \\
\hline$\lambda 3$ & 12.51 \\
\hline$\lambda 4$ & 13.07 \\
\hline$\lambda 5$ & 12.27 \\
\hline$\lambda 6$ & 12.35 \\
\hline$\lambda 7$ & 12.43 \\
\hline$\lambda 8$ & 12.24 \\
\hline$\lambda 9$ & 12.09 \\
\hline$\lambda 10$ & 12.17 \\
\hline$\lambda 11$ & 12.56 \\
\hline$\lambda 12$ & 13.35 \\
\hline$\lambda$ max & 12.52 \\
\hline Inconsistency index & 0.048 \\
\hline Random Inconsistency index (from table 1) & 0.478 \\
\hline Inconsistency rate & 0.0998 \\
\hline
\end{tabular}

Now, based on inconsistency rate calculating and consequently the consistency of the fuzzy number matrix for calculations, we consider ranking by Chang and Buckley fuzzy algorithms.

\section{Results of fuzzy AHP Method by Chang fuzzy algorithm}

According to the calculating steps of Chang fuzzy method, the final weight and rank of factors have been calculated based on Table 7 and shown in chart 3: 
Table 7- weight and rank of effective agents- Chang algorithm

\begin{tabular}{|c|l|c|c|}
\hline component & \multicolumn{1}{|c|}{ Effective agents } & Final weight & rank \\
\hline E1 & determining goals of organization & 0.308 & 1 \\
\hline E2 & management commitment & 0.000 & 8 \\
\hline E3 & forming management committee and expert working group & 0.005 & 7 \\
\hline E4 & assessing needs and creating a proper background & 0.225 & 2 \\
\hline E5 & choosing the correct software & 0.000 & 8 \\
\hline E6 & programming for gradually implementing the software & 0.127 & 5 \\
\hline E7 & creating a strong database & 0.000 & 8 \\
\hline E8 & compiling and performing comprehensive guidelines & 0.168 & 3 \\
\hline E9 & having expert human resources & 0.000 & 8 \\
\hline E10 & culturalizationand comprehensive education for users & 0.136 & 4 \\
\hline E11 & informational structure required for documenting the results & 0.031 & 6 \\
\hline E12 & determining the performance key indices & 0.000 & 8 \\
\hline
\end{tabular}

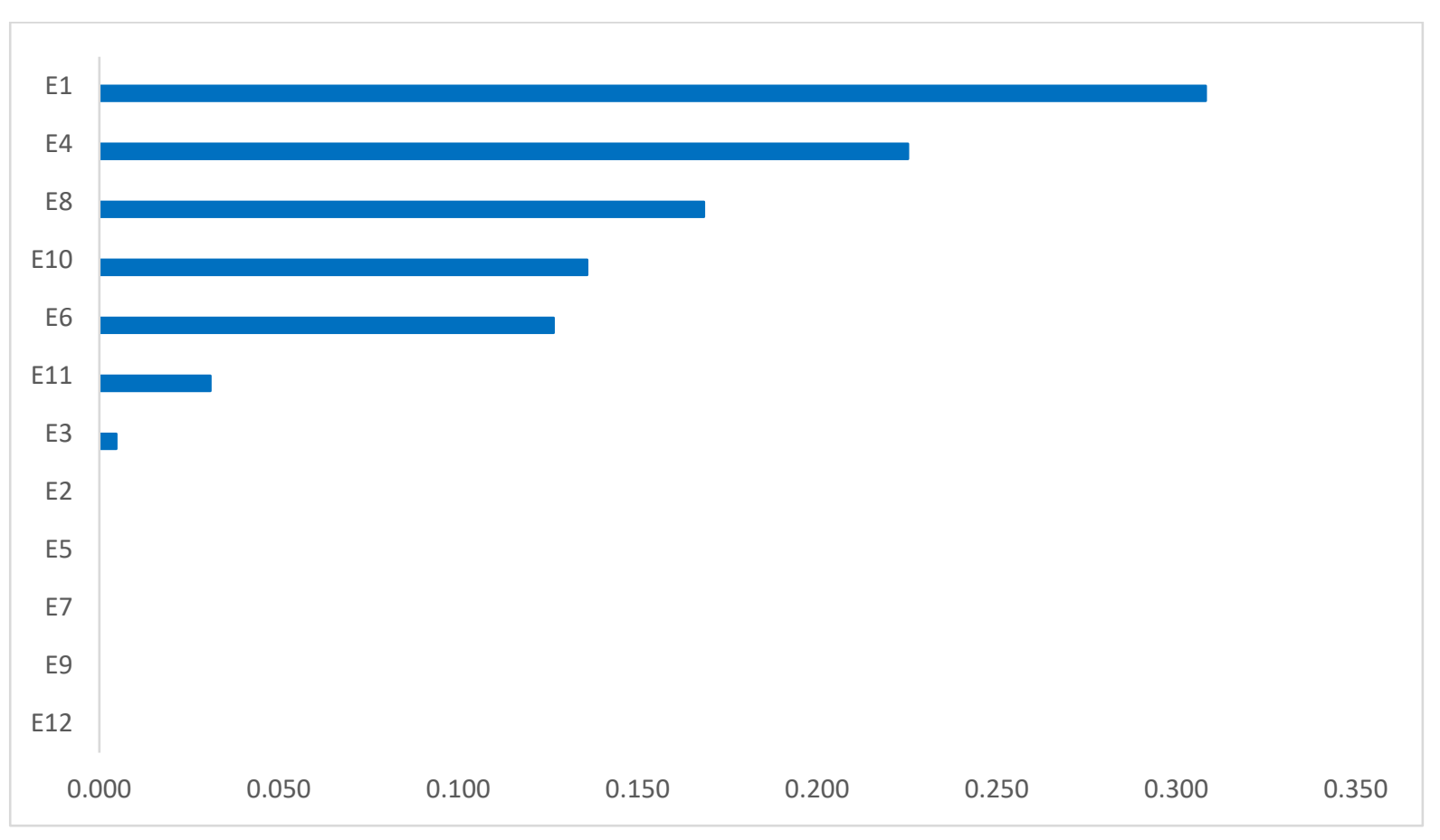

Chart 3- showing rank and priority of the effective agents- Chang algorithm

As shown in the above table and chart, "determining goals of organization", "assessing needs and creating a proper background" and "compiling and performing comprehensive guidelines" have a high priority and importance.

\section{Results of fuzzy AHP Method by Buckley fuzzy algorithm}

According to the 6-step calculating of Buckley fuzzy method, the final weight and rank of factors have been calculated based on Table 8 and shown in chart 4 : 
Table 8- ranking the effective agents- Buckley algorithm

\begin{tabular}{|c|l|c|c|}
\hline Component & \multicolumn{1}{|c|}{ Effective agents } & Final weight & rank \\
\hline E1 & determining goals of organization & 0.150 & 1 \\
\hline E2 & management commitment & 0.057 & 9 \\
\hline E3 & forming management committee and expert working group & 0.070 & 7 \\
\hline E4 & assessing needs and creating a proper background & 0.124 & 2 \\
\hline E5 & choosing the correct software & 0.061 & 8 \\
\hline E6 & programming for gradually implementing the software & 0.098 & 4 \\
\hline E7 & creating a strong database & 0.055 & 10 \\
\hline E8 & compiling and performing comprehensive guidelines & 0.095 & 5 \\
\hline E9 & having expert human resources & 0.053 & 12 \\
\hline E10 & culturalization and comprehensive education for users & 0.101 & 3 \\
\hline E11 & informational structure required for documenting the results & 0.080 & 6 \\
\hline E12 & determining the performance key indices & 0.055 & 11 \\
\hline
\end{tabular}

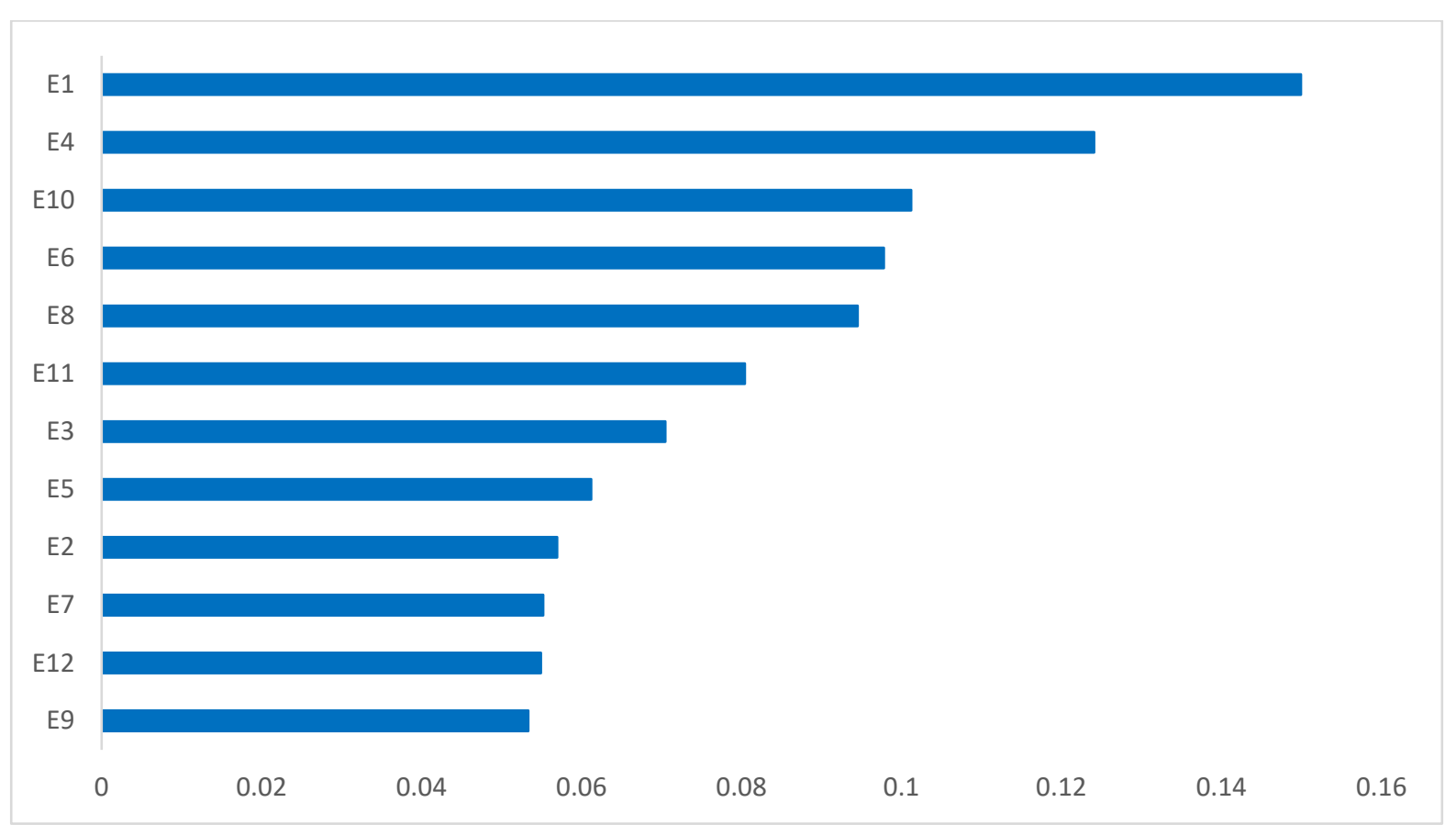

Chart 3- showing rank and priority of the effective agents- Buckley algorithm

As shown in the above table and chart, "determining goals of organization", "assessing needs and creating a proper background" and "culturalization and comprehensive education for users" have a high priority and importance.

\section{Comparing the results of the fuzzy AHP method (Chang fuzzy algorithm and Buckley fuzzy algorithm)}

As shown in Table 8, in Buckley fuzzy algorithm and Chang's algorithm, risks and factors of "determining goals of organization", "assessing needs and creating a proper background" have the highest rank and priority similarly, and " creating a strong database" and "having expert human resources" have the least importance and priority and other factors have the middle ranks. According to the information and data obtained in Chang fuzzy Algorithm, this algorithm is not proper for this research because of zero weights ( 5 factors of zero weight); as a result, the results of the Buckley fuzzy algorithm are used for controlling and managing the factors effective on implementing CMMS. 
Table 8- comparing the results of Chang and Buckley fuzzy AHP algorithms

\begin{tabular}{|c|l|c|c|c|c|}
\hline \multirow{2}{*}{ component } & \multicolumn{1}{|c|}{ Effective agents } & \multicolumn{2}{c|}{ Chang fuzzy algorithm } & \multicolumn{2}{c|}{ Buckley fuzzy algorithm } \\
\cline { 3 - 6 } & & weight & rank & weight & rank \\
\hline E1 & determining goals of organization & 0.308 & 1 & 0.150 & 1 \\
\hline E2 & management commitment & 0.000 & 8 & 0.057 & 9 \\
\hline E3 & $\begin{array}{l}\text { forming management committee and } \\
\text { expert working group }\end{array}$ & 0.005 & 7 & 0.070 & 7 \\
\hline E4 & $\begin{array}{l}\text { assessing needs and creating a proper } \\
\text { background }\end{array}$ & 0.225 & 2 & 0.124 & 2 \\
\hline E5 & choosing the correct software & 0.000 & 8 & 0.061 & 8 \\
\hline E6 & $\begin{array}{l}\text { programming for gradually implementing } \\
\text { the software }\end{array}$ & 0.127 & 5 & 0.098 & 4 \\
\hline E7 & creating a strong database & 0.000 & 8 & 0.055 & 10 \\
\hline E8 & $\begin{array}{l}\text { compiling and performing comprehensive } \\
\text { guidelines }\end{array}$ & 0.168 & 3 & 0.095 & 5 \\
\hline E9 & having expert human resources & 0.000 & 8 & 0.053 & 12 \\
\hline E10 & $\begin{array}{l}\text { culturizing and comprehensive education } \\
\text { for users }\end{array}$ & 0.136 & 4 & 0.101 & 3 \\
\hline E11 & $\begin{array}{l}\text { informational structure required for } \\
\text { documenting the results }\end{array}$ & 0.031 & 6 & 0.080 & 6 \\
\hline E12 & determining the performance key indices & 0.000 & 8 & 0.055 & 11 \\
\hline
\end{tabular}

Rate of observing the effective factors on implementing CMMS in Amir kabir petrochemical company

The applied rate of the risks and factors identified in Amir Kabir Petrochemical based on questionnaire 4 is shown in the table 9.

Table 9- rate of observing the effective factors in Amir Kabir petrochemical company

\begin{tabular}{|c|c|c|c|c|c|}
\hline \multirow[t]{2}{*}{ row } & \multirow[t]{2}{*}{ effective factors } & \multicolumn{4}{|c|}{ rate of observing and implementing the factors } \\
\hline & & Very good & good & average & weak \\
\hline 1 & determining goals of organization & & & 2 & 12 \\
\hline 2 & management commitment & & 1 & 4 & 9 \\
\hline 3 & $\begin{array}{l}\text { forming management committee and expert } \\
\text { working group }\end{array}$ & & 3 & 5 & 6 \\
\hline 4 & $\begin{array}{l}\text { assessing needs and creating a proper } \\
\text { background }\end{array}$ & & 4 & 7 & 3 \\
\hline 5 & choosing the correct software & 11 & 2 & & \\
\hline 6 & $\begin{array}{l}\text { programming for gradually implementing the } \\
\text { software }\end{array}$ & 1 & 13 & & \\
\hline 7 & creating a strong database & & 4 & 10 & \\
\hline 8 & $\begin{array}{l}\text { compiling and performing comprehensive } \\
\text { guidelines }\end{array}$ & 2 & 12 & & \\
\hline 9 & having expert human resources & & 4 & 3 & 7 \\
\hline 10 & $\begin{array}{l}\text { culturizing and comprehensive education for } \\
\text { users }\end{array}$ & & & 1 & 13 \\
\hline 11 & $\begin{array}{l}\text { informational structure required for documenting } \\
\text { the results }\end{array}$ & & 9 & 4 & 1 \\
\hline 12 & determining the performance key indices & & 6 & 8 & \\
\hline
\end{tabular}


Lack of identifying and paying attention to the priority and importance of each factor leads to improper control of the factors and risks that based on table 9 and acknowledgment of the company's management, the lack of precise identification of factors and risks and as a result lack of attention and correctly control the factors has definitely led to dissatisfaction and failure of the project of the Computerized Maintenance Management System. Now, given the findings and results of the research, the management of Amir Kabir Petrochemical Company, together with the expert work group, is addressing the weaknesses and improving the state of CMMS in the company with a high priority.

\section{Discussion and Conclusion}

In this research, the risks and factors affecting on implementing CMMS were identified through library research, questionnaire and interviews with experts and to rank the risks, Buckley and Chang fuzzy AHP algorithms were used. Most previous research on this topic have been conducted using the ordinary multi-criteria decision making methods such as AHP and definite numbers. Using fuzzy numbers is more consistent with verbal and sometimes vague phrases of human, so it is better to use the fuzzy numbers to make decisions in the real world. In Buckley fuzzy algorithm and Chang algorithm, risks and factors of "determining goals of organization", "assessing needs and creating a proper background" have the highest rank and priority similarly, and " creating a strong database" and "having expert human resources" have the least importance and priority and other factors have the middle ranks. But, according to the information and data obtained in Chang fuzzy Algorithm, this algorithm is not proper for this research because of having zero weights; as a result, the results of the Buckley fuzzy algorithm are used for controlling and managing the factors effective on implementing CMMS and according to the applied rate of the identified factors and risk in Amir Kabir Petrochemical,it was found that the identification and significance of the risks and the factors affecting on the implementation of CMMS have not been accurate and correct and thus led to the dissatisfaction and failure of the project of the Computerized Maintenance Management System . Now, given the findings and results of the research, the management of Amir Kabir Petrochemical Company, together with the expert work group, is addressing the weaknesses and improving the state of CMMS in the company.

In the future research, we can use Balanced Scorecard to identify and categorize the factors and other decision making methods such as fuzzy TOPSIS algorithm to rank and weight. It is also suggested that this research be conducted with a wider and larger statistical population and sample.

\section{References}

[1] Karimi, Ayar, KolahiRanji, Saeid, 2015, studying and prioritizing the barriers to Implementing Computerized Maintenance Management System in organization using a combination of fuzzy TOPSIS and fuzzy DEMATEL methods, Case study: Continent Plateau Oil Company.

[2] Soodani, Alireza, Rezaee, Yasin, 2018, Studying the risk assessment technique of analyzing the error states and its effects FMEA, the second national conference on knowledge and technology of agricultural science, natural resources and environment of Iran, Tehran, the Institute of holding development-center conferences of Knowledge and Technology of Sam of Iranians.

[3] Maktoobian, Athena, finding and rating the CMMS implementation problems, the special journal on Management of Physical Assets, Maintenance, Etminan magazine, the first edition, No.4.

[4] MalekiNejad, Fayegh, Hamta, Nima, 2017, studying the effect of utilizing Computerized Maintenance Management Systemon maintenance indices, the fourteenth Conference on manufacturing and producing Engineering of Iran, Arak, Industrial University of Arak, Association of Manufacturing Engineering of Iran.

[5] Habibi, Arash, 2012, Applied training of SPSS, second edition.

[6] Lopez, M. A. and Marquez, A. C. and Gomez, J. F. (2018). The Integration of Open Reliability, Maintenance, and Condition Monitoring Management System, Springer link, pp. 43-78.

[7] O\&M. (2010). Best Practices Guide, Release 3.0, U.S. Department of energy, 4.1, pp.45-47

[8] Herbaty, F. (1990). Handbook of Maintenance Management, Noyes Publications, NJ, p. 306.

[9] Zare, A. and Feylizadeh, M. R. and Mahmoudi, A. (2018). Suitable Cumputerized Maintenance Management System Selection using grey group TOPSIS and fuzzy group VIKOR, Volume 7 Issue 4, pp. 341-358

[10] ISO 31000, (2009), Risk Management-Principles and guidelines, Edit 2018

[11] PMI. (2013). Project Management Body of Knowledge (PMBOK). 5thEd. Project Management Institute (PMI) Pub., USA.

[12] Farahani, A., \&Gonei, A. (2010). The Challenges of CMMS software in Iran. The sixth International Conference on Software, Institute for Productivity and Human Resources.

[13] Fortin, John. and Bloomfield, Priscilla. And Mahaz, Joseph. And Alfaqih, Laith. (2018). Aviation; Data and Information Technology; Maintenance and Preservation, Internal Conference, Project 09-14.

[14] Blaszczyk A., Wisniewski Z. (2018). Requirements for IT Systems of Maintenance Management. In: Karwowski W., Trzcielinski S., Mrugalska B., Di Nicolantonio M., Rossi E. (eds) Advances in anufacturing, Production Management and Process Control. AHFE 2018. Advances in Intelligent Systems and Computing, vol 793. Springer, Cham

[15] Wienker, M. and Henderson, K. and Volkerts, J. (2016). Procedia Engineering, Elsevier

[16] Gogus, O. and Boucher, T. O. (1998). Strong Transitivity, Rationality and Weak Monotonicity in Fuzzy Pairwise Comparisons. Fuzzy Sets and Systems, 94, 133-144

[17] Buckley, J. (1985). Fuzzy hierarchical analysis, Fuzzy Sets and Systems 17, 233-247.

[18] Aczel, J. and Saaty, T. L. (1983). Procedures for synthesizing ratio judgments, J. Math. Psychology 27, 93-102.

[19] Chang, D. Y. (1996). Applications of the extent analysis method on fuzzy AHP. European Journal of Operational Research, 95, 649655 